\title{
EKSPERIMENTASI MODEL PEMBELAJARAN KOOPERATIF TIPE JIGSAW YANG BERORIENTASI PADA PENEMUAN TERBIMBING DENGAN PENGGUNAAN ALAT PERAGA PADA MATERI BANGUN DATAR SEGI EMPAT DITINJAU DARI KEMAMPUAN PENALARAN MATEMATIKA
}

\author{
Nosa Putri Djumaliningsih, Riyadi, Gatut Iswahyudi
}

\begin{abstract}
This research aims to find out: (1) which one providing better mathematics learning achievement, the learning using guided inquiry-oriented Jigsaw type of cooperative learning model, Jigsaw type of cooperative or conventional learning model in rectangular flat structure material, (2) which one having mathematics learning achievement, the student with high, medium, or low mathematics reasoning skill in rectangular flat structure material, (3) in each mathematics reasoning skill (high, medium, and low), which one providing better learning achievement between guided inquiry-oriented Jigsaw type of cooperative learning model with visual aid use, Jigsaw type of cooperative or conventional learning model in rectangular flat structure material, (4) in each learning model (guided inquiry-oriented Jigsaw type of cooperative learning model with visual aid use, Jigsaw type of cooperative or conventional), which one providing better mathematics learning achievement, the students with high, medium or low mathematics reasoning skill in rectangular flat structure material.

This study belonged to a quasi-experimental research with a $3 \times 3$ factorial design taken place in VII grade of SMPN Ponorogo in second semester of 2011/2012 school year. The population of research was all VII graders of Junior High Schools in Ponorogo, consisting of 51 school. The sampling technique used was stratified cluster random sampling. The classification of school was made according to National Examination value in the school year of 2010/2011. The samples of research were 280 students from SMPN 2 Ponorogo for high classification, SMPN 6 Ponorogo for medium classification, SMPN 2 Babadan for low classification. The data of mathematic reasoning skill and learning achievement were collected using a multiple-choice test. Technique of analyzing data used was a two-way variance analysis with different cells.

The conclusions of research were (1) there was an effect of learning model on the learning achievement $\left(\mathrm{F}_{\text {obs }}=8.10>\mathrm{F}_{\text {table }}=3\right)$, from inter-row mean comparative test, it could be found that the guided inquiry-oriented Jigsaw type of cooperative learning model with visual aid use (marginal mean of 74.0833) provided better achievement than Jigsaw type of cooperative did (marginal mean of 69.5652) and both of them provided better achievement than the conventional learning model did (marginal mean of 65); (2) there was an effect of student mathematics reasoning skill on the learning achievement $\left(\mathrm{F}_{\mathrm{obs}}=32.74>\mathrm{F}_{\text {table }}=3\right)$, from interrow mean comparative test, it could be found that the students with high reasoning skill (marginal mean of 74.8785) provided reasoning skill equaling to the students with medium reasoning skill did (marginal mean of 71.5506), and both of them provided better achievement than the students with low reasoning skill did (marginal mean of 60.8571); (3) in high reasoning skill, the guided inquiry-oriented Jigsaw type of cooperative learning model with visual aid use provided achievement equaling to the Jigsaw type of cooperative did and both of them provided achievement equaling to the conventional learning model did, while in medium and low reasoning skill, the three learning model provided the same learning achievement; (4) in the guided inquiry-oriented Jigsaw type of cooperative learning model with visual aid use, the students with high mathematics reasoning skill had mathematics learning achievement as same as those with medium mathematics reasoning skill had, and both of them had mathematics learning achievement as same as those with low mathematics reasoning skill had, while in Jigsaw type of cooperative and conventional learning model, the students with high mathematics reasoning skill had mathematics learning achievement as same as those with medium and low mathematics reasoning skill had.
\end{abstract}




\section{PENDAHULUAN}

Kemajuan suatu bangsa sangat ditentukan oleh kualitas sumber daya yang dimiliki, baik sumber daya alam maupun sumber daya manusia. Sumber daya manusia yang berkualitas pada umumnya lahir melalui proses pendidikan yang baik dan dari institusi pendidikan yang bermutu. Selain itu, matematika merupakan mata pelajaran yang diajarkan mulai jenjang pendidikan dasar. Matematika timbul karena olah pikir manusia yang berhubungan dengan ide, proses dan penalaran yang disusun secara konsisten dengan mempergunakan logika deduktif. Tujuan pendidikan matematika di sekolah adalah untuk mempersiapkan anak didik agar sanggup menghadapi perubahan-perubahan keadaan dalam kehidupan dunia yang senantiasa berubah, melalui latihan bertindak atas dasar pemikiran logis, rasional, kritis, cermat, kreatif dan efisien.

Dengan demikian dapat dikatakan bahwa diberikannya pelajaran matematika adalah memberikan tekanan pada penataan nalar, pembentukan sikap siswa, serta keterampilan dalam menerapkan matematika di kehidupan sehari-hari.

Berdasarkan observasi yang telah dilakukan peneliti pada bulan Februari 2012 di SMPN 6 Ponorogo kelas VII A, VIIB dan VIIC pada materi himpunan, sering dijumpai banyak siswa yang masih kurang daya nalarnya (khususnya dalam menyelesaikan soal-soal matematika), yaitu dengan melihat jawaban siswa yang tidak logis, berbelit- belit atau tidak tepat pada permasalahan yang ditanyakan soal, sehingga siswa tidak dapat menyelesaikan soal matematika tersebut dengan baik. Pada Ujian Nasional yang dilaksanakan di Ponorogo Tahun 2011, rata-rata nilai Ujian Nasional siswa SMP pada mata pelajaran Matematika di kabupaten Ponorogo menempati tempat ke26 dari 38 kabupaten dan kota di Jawa Timur dengan nilai rata-rata 6,96 jauh di bawah rata-rata propinsi yaitu 7,71. Jika dilihat lebih lanjut pada setiap kemampuan yang diujikan, ada beberapa materi dengan daya serap siswa kurang dari 70. Materimateri pada semester II kelas VII SMP tersebut terlihat pada Tabel 1.

Kesulitan yang dialami siswa pada mata pelajaran matematika tidak hanya bersumber dari kemampuan siswa, akan tetapi ada faktor yang turut menentukan keberhasilan siswa dalam belajar matematika (Soedjadi, 2000), yaitu faktor internal meliputi sikap, perkembangan kognitif, kemampuan siswa, jenis kelamin siswa serta faktor yang berasal dari luar diri siswa antara lain meliputi keadaan sosial ekonomi, lingkungan, model mengajar yang dipakai guru, dan sarana atau fasilitas yang digunakan.

Pemilihan model mengajar yang tepat akan membantu siswa untuk lebih aktif dalam belajar, sehingga proses dan hasil belajar siswa dapat meningkat. Untuk mengurangi siswa yang hanya bergantung kepada teman kelompok dapat menggunakan kooperatif tipe Jigsaw yang memberikan tanggung jawab penguasaan materi terhadap 
siswa dan menuntun siswa untuk kreatif mengumpulkan informasi mengenai materi tersebut. Dalam pembelajaran kooperatif Jigsaw (Anita Lie, 2007), guru memperhatikan pengetahuan yang telah dimiliki siswa dan membantu siswa mengaktifkan pengetahuan materi sebelumnya agar bahan pelajaran menjadi lebih bermakna. Sementara itu menurut Slavin (2008), kunci pembelajaran kooperatif Jigsaw adalah tiap siswa bergantung pada teman satu timnya untuk dapat memberikan informasi yang diperlukan supaya dapat berkinerja baik pada saat penilaian.

Tabel 1 Daftar Materi Uji Pada Semester II Kelas VII Ujian Nasional Tahun 2011 Siswa SMP Kab. Ponorogo

\begin{tabular}{|l|l|l|l|l|}
\hline No & Kemampuan yang Diuji & Kota & Prop & Nas \\
\hline 1. & Menentukan irisan atau gabungan dua himpunan & 75.41 & 79.38 & 77.85 \\
\hline 2. & $\begin{array}{l}\text { Menyelesaikan masalah yang berkaitan dengan irisan atau } \\
\text { gabungan dua himpunan }\end{array}$ & 76.46 & 78.88 & 76.36 \\
\hline 3. & $\begin{array}{l}\text { Menyelesaikan soal yang berkaitan dengan relasi atau } \\
\text { fungsi }\end{array}$ & 72.26 & 79.17 & 78.55 \\
\hline 4. & $\begin{array}{l}\text { Mengitung besar sudut yang melibatkan sudut dalam dan } \\
\text { sudut luar segitiga }\end{array}$ & 84.17 & 88.49 & 87.80 \\
\hline 5. & $\begin{array}{l}\text { Menghitung besar sudut yang terbentuk jika dua garis } \\
\text { sejajar berpotongan dengan garis lain }\end{array}$ & 88.10 & 87.67 & 85.55 \\
\hline 6. & Menghitung luas bangun datar & 77.55 & 78.21 & 75.75 \\
\hline 7. & $\begin{array}{l}\text { Menyelesaikan masalah yang berkaitan dengan luas bangun } \\
\text { datar }\end{array}$ & 63.94 & 68.08 & 66.39 \\
\hline 8. & $\begin{array}{l}\text { Menyelesaikan soal keliling bangun datar dan penggunaan } \\
\text { konsep keliling dalam keseharian }\end{array}$ & 68.61 & 75.25 & 72.36 \\
\hline
\end{tabular}

Dalam penemuan terbimbing, siswa perlu dibiasakan untuk memecahkan masalah, menemukan sesuatu yang berguna bagi dirinya, dan bergelut dengan ide-ide. Guru tidak memberikan pengetahuan kepada siswa. Siswa harus mengkonstruksi pengetahuan di benak mereka sendiri. Selain itu, dalam mempelajari suatu konsep atau prinsip-prinsip matematika diperlukan pula pembelajaran yang inovatif dan pengalaman melalui benda-benda nyata (konkret) yang dapat digunakan sebagai jembatan bagi siswa untuk berpikir abstrak.

Model Pembelajaran Kooperatif Tipe Jigsaw yang Berorientasi pada Penemuan

\section{Terbimbing dengan Penggunaan Alat} Peraga.

Dengan penggunaan tipe Jigsaw ini diharapkan dapat mengatasi permasalahan kurangnya interaksi antar siswa serta antara siswa dan guru, dengan kata lain mampu mangaktifkan interaksi siswa dalam pelaksanaan pembelajaran. Di pihak lain, dalam penemuan terbimbing, siswa perlu dibiasakan untuk memecahkan masalah, menemukan sesuatu yang berguna bagi dirinya, dan bergelut dengan ide-ide sehingga pembelajaran lebih bermakna. Selain itu, dengan menggunakan alat peraga dapat membantu siswa saat pelajaran 
matematika, karena objek matematika yang bersifat abstrak dapat dikongkritkan.

a.Guru menjelaskan kepada seluruh siswa tentang akan diterapkannya model pembelajaran kooperatif tipe Jigsaw, sebagai suatu variasi model pembelajaran.

b.Guru menjelaskan kepada siswa tentang pola kerjasama.

c.Guru tidak menerangkan materi yang akan dipelajari karena siswa akan menemukan konsep dari materi tersebut dalam belajar kelompok sehingga pengetahuan yang diperoleh akan lebih dipahami berdasarkan pengalaman belajar masing-masing.

d.Para siswa dibagi dalam kelompokkelompok kecil yang heterogen. Setiap kelompok diijinkan untuk mencari referensi sebanyak mungkin.

e.Ketua kelompok membagi tugas guru kelompok (misalnya, setiap siswa dalam kelompok mendapat 1 sub materi yang berbeda berupa LKS (Lembar Kerja Siswa yang berorientasi pada penemuan terbimbing yaitu berisi petunjuk-petunjuk yang mengarahkan pada materi ajar).

f.Setelah setiap anggota kelompok mendapatkan sub materi, siswa diminta mengambil alat peraga yang sesuai dengan sub materinya.

g.Dari beberapa kelompok yang telah terbentuk, anggota kelompok yang mendapat soal yang sama bertemu untuk mendiskusikan soal tersebut sampai mengerti benar cara menyelesaikan soal tersebut.
h.Kemudian siswa itu kembali ke kelompok asalnya dan bergantian menjelaskan hasil penyelesaian soal kepada anggota dalam kelompok asal.

i.Siswa melakukan presentasi hasil kerja kelompok dengan menggunakan alat peraga.

j.Guru bersama siswa mendiskusikan hasil kerja kelompok.

k.Guru memperkuat konsep materi ajar dengan memberikan pertanyaan langsung.

1.Guru mengecek kemampuan belajar siswa dengan memberikan tes.

m. Siswa mengumpulkan jawaban tes.

n.Guru bersama siswa membahas soal tes.

\section{Model Pembelajaran Kooperatif Tipe Jigsaw}

Dalam model pembelajaran kooperatif Jigsaw, setiap siswa menjadi anggota kelompok asal (home group) dan juga sebagai kelompok ahli (expert group) Siswa dalam kelompok ahli bertanggung jawab terhadap penguasaan materi yang menjadi bagian yang dipelajari dan berkewajiban mengajarkan kepada siswa lain dalam kelompoknya (dalam Sumarsono,2005). Selain itu, siswa bekerja dengan sesama siswa dalam suasana kooperatif dan mempunya banyak kesempatan untuk mengolah informasi dan meningkatkan keterampilan berkomunikasi (Anita Lie, 2007). Adapun langkah-langkah pada model kooperatif tipe Jigsaw adalah sebagai berikut:

a.Guru menjelaskan kepada seluruh siswa tentang akan diterapkannya model pembelajaran kooperatif tipe Jigsaw, sebagai suatu variasi model pembelajaran. Guru 
menjelaskan kepada siswa tentang pola kerjasama.

b.Para siswa dibagi dalam kelompokkelompok kecil yang heterogen. Setiap kelompok diberi lembar kerja siswa tertentu untuk dikerjakan.

c.Ketua kelompok membagi tugas guru untuk dikerjakan oleh masing-masing anggota kelompok (misalnya, setiap siswa dalam kelompok mendapat 1 soal yang berbeda).

d.Dari beberapa kelompok yang telah terbentuk, anggota kelompok yang mendapat soal yang sama bertemu untuk mendiskusikan soal tersebut sampai mengerti benar cara menyelesaikan soal tersebut.

e.Kemudian siswa itu kembali ke kelompok asalnya dan bergantian menjelaskan hasil penyelesaian soal kepada anggota dalam kelompok asal.

f.Guru beserta siswa membahas hasil diskusi kelompok sehingga diperoleh suatu kesimpulan.

\section{Kemampuan Penalaran Matematika}

Istilah penalaran atau reasoning dijelaskan oleh Copi (dalam Fajar Shodiq, 2004) sebagai berikut:

"Reasoning is a special kind of thinking in which inference takes place, in which conclusions are drawn from premises"

sehingga penalaran merupakan merupakan kegiatan, proses atau aktivitas berpikir untuk menarik suatu kesimpulan atau membuat suatu pernyataan baru berdasar pada beberapa pernyataan yang diketahui benar ataupun yang dianggap benar atau yang diasumsikan kebenarannya yang disebut dengan premis. Jujun S. Suriasumantri (1982) mengungkapkan bahwa penalaran merupakan suatu proses berpikir dalam menarik suatu kesimpulan yang berupa pengetahuan.

\section{Kerangka Berpikir}

1. Kaitan antara model pembelajaran dengan prestasi belajar matematika siswa.

Penggunaan tipe Jigsaw ini diharapkan dapat mengatasi permasalahan kurangnya interaksi antar siswa serta antara siswa dan guru, dengan kata lain mampu mangaktifkan interaksi siswa dalam pelaksanaan pembelajaran. Dalam mempelajari suatu konsep atau prinsipprinsip matematika diperlukan pembelajaran yang inovatif dan pengalaman melalui benda-benda nyata (konkret) yang dapat digunakan sebagai jembatan bagi siswa untuk berpikir abstrak. Di pihak lain, dalam penemuan terbimbing, siswa perlu dibiasakan untuk memecahkan masalah, menemukan sesuatu yang berguna bagi dirinya, dan bergelut dengan ide-ide. Sehingga dapat dikatakan bahwa kooperatif tipe Jigsaw berorientasi penemuan terbimbing dengan penggunaan alat peraga lebih baik dibandingkan dengan kooperatif Jigsaw atau model pembelajaran konvensional.

2. Kaitan antar kemampuan penalaran matematika dengan prestasi belajar matematika siswa. 
Menurut Soedjadi, faktor internal yang mempengaruhi keberhasilan siswa dalam belajar dan meningkatkan prestasi belajarnya salah satunya adalalah kemampuan yang didalamnya termasuk kemampuan penalaran. Dengan demikian siswa yang mempunyai penalaran baik akan lebih memahami tentang konsep dari suatu materi ajar. Penguasaan materi ajar yang baik dapat meningkatkan prestasi belajar siswa.

3. Pengaruh masing-masing tingkatan kemampuan penalaran untuk berbagai model pembelajaran terhadap prestasi belajar siswa.

Penalaran merupakan suatu proses penting dalam pengerjaan matematika. Tujuan terpenting dari pembelajaran matematika adalah mengajarkan kepada siswa penaaran logis. Model pembelajaran Jigsaw akan mengaktifkan kegiatan siswa dan penemuan terbimbing akan membiasakan siswa menggunakan idenya serta alat peraga akan membantu siswa memahami objek matematika yang abstrak.

4. Pengaruh masing-masing model pembelajaran untuk berbagai tingkatan kemampuan penalaran matematika terhadap prestasi belajar siswa.

Dalam pembelajaran kooperatif ini, guru memperhatikan pengetahuan yang telah dimiliki oleh siswa atau latar belakang pengalaman siswa dan membantu siswa mengaktifkan skemata ini agar bahan pelajaran menjadi lebih bermakna.
Dengan penemuan terbimbing dan alat peraga menuntun siswa menggunakan penalarannya untuk menyelesaikan permasalahan.

\section{Instrumen dan Uji Coba Instrumen}

Dalam upaya mendapatkan data yang akurat maka instrumen tes prestasi belajar dan tes kemampuan penalaran yang haruslah memenuhi kriteria instrumen yang baik.

Tes prestasi belajar dan teskemampuan penalaran siswa

Untuk instrumen yang berupa tes akan diuji validitas, tingkat kesukaran, daya beda, dan reliabilitasnya. Validitas tes yang digunakan adalah validitas isi, yakni ditinjau dari kesesuaian isi tes dengan isi kurikulum yang hendak diukur. Untuk keperluan ini, prosedur yang harus ditempuh dalam penyusunan tes adalah:

a. Menentukan kompetensi dasar dan indikator yang akan diukur sesuai dengan materi dan tujuan kurikulum untuk tes prestasi belajar sedangkan tes penalaran menentukan indikator dalam penalaran matematika.

b. Menyusun kisi-kisi tes berdasarkan kompetensi dasar dan indikator yang dipilih.

c. Munyusun butir tes berdasarkan kisikisi yang telah dibuat.

d. Melakukan penilaian terhadap butir tes.

\section{Teknik Analisis Data}

Untuk keperluan uji hipotesis, data hasil penelitian ini diolah menggunakan analisis variansi. Menurut Budiyono (2009:185), terdapat 4 syarat yang harus 
dipenuhi dalam menggunakan analisis variansi, yaitu:

1. Setiap sampel diambil secara random dari populasinya.

2. Masing-masing populasi saling independen dan masing-masing data amatan saling independen di dalam kelompoknya.

3. Setiap populasi berdistribusi normal (sifat normalitas populasi).

4. Populasi mempunyai variansi yang sama (sifat homogenitas variansi populasi).

\section{Analisis Variansi Dua Jalan dengan Sel}

\section{Tak Sama}

Penelitian ini menggunakan 2 variabel bebas dan satu variabel terikat. Adapun kedua variabel bebas tersebut adalah model pembelajaran dan kemampuan penalaran matematika. Untuk variabel terikatnya ada 1 yaitu prestasi belajar. Oleh karena itu, menurut Budiyono (2009:206), untuk menguji signifikansi efek 2 variabel bebas terhadap satu variabel terikat dapat digunakan analisis variansi dua jalan. Karena jumlah siswa untuk setiap tingkat kemampuan penalaran yang dimiliki berbeda dan jumlah siswa dalam tiap-tiap kelompok eksperimen dan kelompok kontrol juga berbeda, maka jumlah data untuk setiap sel dimungkinkan berbeda-beda sehingga analisis variansi dua jalan yang digunakan adalah analisis variansi dua jalan dengan sel tak sama

\section{a. Hipotesis}

Misalnya variabel model pembelajaran (A) yang mempunyai nilai $\mathrm{a}_{1}$, $a_{2}$ dan $a_{3}$ dan kolom menyatakan variabel kemampuan penalaran matematika (B) mempunyai nilai $b_{1}, b_{2}, b_{3}$.

1) $\mathrm{H}_{0 \mathrm{~A}}$ : tidak ada perbedaan efek penggunaan model pembelajaran kooperatif tipe Jigsaw berorientasi penemuan terbimbing, kooperatif tipe Jigsaw dan model pembelajaran konvensional.

$\mathrm{H}_{1 \mathrm{~A}}$ : ada perbedaan efek penggunaan model pembelajaran kooperatif tipe Jigsaw berorientasi penemuan terbimbing, kooperatif tipe Jigsaw dan model pembelajaran konvensional

$\mathrm{H}_{0 \mathrm{~B}} \quad$ : tidak ada perbedaan efek antar tingkat kemampuan penalaran terhadap prestasi belajar siswa.

$\mathrm{H}_{1} \mathrm{~B}$ : ada perbedaan efek antar tingkat kemampuan penalaran terhadap prestasi belajar siswa

2) $\mathrm{H}_{0 \mathrm{AB}}$ : tidak ada interaksi antara model pembelajaran dan tingkat kemampuan penalaran terhadap prestasi belajar siswa.

$\mathrm{H}_{1 \mathrm{AB}}$ : ada interaksi antara antara model pembelajaran dan tingkat kemampuan penalaran terhadap prestasi belajar siswa. 


\section{PEMBAHASAN}

\section{Data Penalaran Matematika}

Dari data penalaran matematika yang sudah masuk, diperoleh keterangan seperti pada Tabel 3 .

\section{Data Prestasi Belajar Matematika}

Dari data prestasi belajar yang sudah masuk, diperoleh keterangan seperti pada Tabel 4.

Tabel 2. Rancangan Penelitian

\begin{tabular}{|l|l|l|l|}
\hline Kodel Pembelajaran $(\mathbf{A})$ & $\begin{array}{l}\text { Tinggi } \\
\left(\mathbf{b}_{\mathbf{1}}\right)\end{array}$ & $\begin{array}{l}\text { Sedang } \\
\left(\mathbf{b}_{\mathbf{2}}\right)\end{array}$ & $\begin{array}{l}\text { Rendah } \\
\left(\mathbf{b}_{\mathbf{3}}\right)\end{array}$ \\
\hline Jigsaw Termodifikasi $\left(\mathrm{a}_{1}\right)$ & $\mathrm{ab}_{11}$ & $\mathrm{ab}_{12}$ & $\mathrm{ab}_{13}$ \\
\hline Jigsaw $\left(\mathrm{a}_{2}\right)$ & $\mathrm{ab}_{21}$ & $\mathrm{ab}_{22}$ & $\mathrm{ab}_{23}$ \\
\hline Konvensional $\left(\mathrm{a}_{3}\right)$ & $\mathrm{ab}_{31}$ & $\mathrm{ab}_{32}$ & $\mathrm{ab}_{33}$ \\
\hline
\end{tabular}

Tabel 3 Sebaran Kategori Penalaran Matematika Siswa

\begin{tabular}{|l|c|c|c|c|}
\hline \multirow{2}{*}{ Model Pembelajaran } & \multicolumn{4}{|c|}{ Jumlah Siswa untuk Tiap Kategori Penalaran } \\
\cline { 2 - 5 } & Tinggi & Sedang & Rendah & Jumlah \\
\hline $\begin{array}{l}\text { Jigsaw berorientasi } \\
\text { penemuan terbimbing } \\
\text { dengan penggunaan alat } \\
\text { peraga }\end{array}$ & 41 & 31 & 24 & 96 \\
\hline Jigsaw & 31 & 29 & 32 & 92 \\
\hline Konvensional & 35 & 29 & 28 & 92 \\
\hline Jumlah & 107 & 89 & 84 & \\
\hline
\end{tabular}

Tabel 4 Rangkuman Data Prestasi Belajar Matematika Siswa

\begin{tabular}{|l|c|c|c|c|}
\hline Kelompok & $\begin{array}{c}\text { Nilai } \\
\text { Terendah }\end{array}$ & $\begin{array}{c}\text { Nilai } \\
\text { Tertinggi }\end{array}$ & $\begin{array}{c}\text { Standart } \\
\text { Deviasi }\end{array}$ & Rata-rata \\
\hline $\begin{array}{l}\text { Jigsaw berorientasi } \\
\text { penemuan terbimbing } \\
\text { dengan penggunaan alat } \\
\text { peraga }\end{array}$ & 36 & 100 & 15.57 & 74.08 \\
\hline Jigsaw & 40 & 96 & 12.38 & 69.57 \\
\hline Konvensional & 32 & 96 & 13.37 & 65 \\
\hline Penalaran Tinggi & 36 & 100 & 12.86 & 74.88 \\
\hline Penalaran Sedang & 32 & 100 & 14.52 & 71.55 \\
\hline Penalaran rendah & 32 & 88 & 11.68 & 60.86 \\
\hline
\end{tabular}

\section{Uji Hipotesis Penelitian}

Perhitungan uji hipotesis dengan analisis variansi dua jalan $3 \times 3$ dengan sel tidak sama dan taraf signifikansi $\alpha=5 \%$, dengan rangkuman perhitungan pada Tabel 5.

a. Pada efek utama baris, yaitu model pembelajaran (A) nilai statistik uji $\mathrm{F}_{\mathrm{obs}}=$ 8.10 dan $\mathrm{F}_{\text {kritik }}=3.00$, maka $\mathrm{F}_{\text {obs }}>\mathrm{F}_{\text {kritik }}$ sehingga disimpulkan $\mathrm{H}_{0 \mathrm{~A}}$ ditolak. Hal ini berarti, pada tingkat signifikansi $\alpha=0.05$ ada perbedaan pengaruh model pembelajaran terhadap prestasi belajar matematika pada pokok bahasan bangun datar segi empat.

b. Pada efek utama kolom, yaitu penalaran matematika siswa (B) nilai statistik uji $\mathrm{F}_{\mathrm{obs}}=$ 32.74 dan $\mathrm{F}_{\text {kritik }}=3.00$, maka $\mathrm{F}_{\text {obs }}>\mathrm{F}_{\text {kritik }}$ sehingga disimpulkan $\mathrm{H}_{0 \mathrm{~B}}$ ditolak, atau dapat dikatakan ada perbedaan pengaruh penalaran matematika siswa terhadap 
prestasi belajar matematika siswa pada pokok bahasan bangun datar segi empat.

c. Pada efek utama interaksi, yaitu interaksi antara model pembelajaran dengan penalaran matematika siswa (AB) nilai statistik uji $\mathrm{F}_{\text {obs }}=5.46$ dan $\mathrm{F}_{\text {kritik }}=2.37$, maka $F_{\text {obs }}>F_{\text {kritik }}$ sehingga disimpulkan $\mathrm{H}_{0 \mathrm{AB}}$ ditolak. Hal ini berarti ada interaksi antara pendekatan pembelajaran dengan penalaran matematika siswa terhadap prestasi belajar siswa pada pokok bahasan bangun datar segi empat.

\section{Uji Lanjut Pasca Anava}

Berdasarkan hasil analisis variansi dua jalan dengan sel tak sama diperoleh bahwa
$\mathrm{H}_{0 \mathrm{~A}}, \mathrm{H}_{0 \mathrm{~B}}, \mathrm{H}_{0 \mathrm{AB}}$ ditolak, sehingga perlu dilakukan uji lanjut untuk mengetahui perbedaan rerata antar baris, kolom dan antar sel pada kolom yang sama. Sebelum melihat hasil uji lanjut, pada Tabel 6 disajikan rangkuman rerata antar sel lengkap dengan rerata marginalnya.

Rangkuman komparasi ganda antar baris, komparasi ganda antar kolom, komparasi rerata antar sel pada baris yang sama, dan dkomparasi rerata antar sel pada kolom yang sama dapat dilihat berturutturut pada Tabel 7, Tabel 8, Tabel 9, dan 10

Tabel 5 Rangkuman Analisis Variansi Dua Jalan dengan Sel Tak Sama

\begin{tabular}{|l|l|l|l|l|l|l|}
\hline \multicolumn{1}{|c|}{ Sumber } & \multicolumn{1}{|c|}{ JK } & \multicolumn{1}{|c|}{ dK } & \multicolumn{1}{|c|}{ RK } & \multicolumn{1}{|c|}{$\mathbf{F}_{\text {obs }}$} & \multicolumn{1}{|c|}{$\mathbf{F}_{\boldsymbol{\alpha}}$} & \multicolumn{1}{|c|}{$\begin{array}{c}\text { Keputusan } \\
\text { Uji }\end{array}$} \\
\hline Model Pembelajaran (A) & 2441.3666 & 2 & 1220.6833 & 8.10 & 3 & $\mathrm{H}_{0 \mathrm{~A}}$ ditolak \\
\hline Penalaran Matematika (B) & 9868.6054 & 2 & 4934.3027 & 32.74 & 3 & $\mathrm{H}_{0 \mathrm{~B}}$ ditolak \\
\hline Interaksi (AB) & 3289.8724 & 4 & 822.4681 & 5,46 & 2.37 & $\mathrm{H}_{0 \mathrm{AB}}$ ditolak \\
\hline Galat (G) & 40845.0207 & 271 & 150.7196 & - & - & - \\
\hline Total & 56444.8651 & 279 & - & - & - & - \\
\hline
\end{tabular}

Tabel 6 Rerata Data Tes Prestasi Belajar Siswa

\begin{tabular}{|l|l|l|l|l|}
\hline \multicolumn{2}{|c|}{ Model Pembelajaran } & \multicolumn{2}{|c|}{ Kemampuan Penalaran Siswa } & \multicolumn{1}{c|}{$\begin{array}{c}\text { Rerata } \\
\text { Marginal }\end{array}$} \\
\cline { 2 - 5 } & Tinggi & Sedang & Rendah & \\
\hline $\begin{array}{l}\text { Jigsaw berorientasi penemuan } \\
\text { terbimbing dengan penggunaan alat } \\
\text { peraga }\end{array}$ & 82.2439 & 76.1290 & 57.5 & 74.0833 \\
\hline Jigsaw & 74.0645 & 69.2414 & 65.5 & 69.5652 \\
\hline Konvensional & 66.9714 & 68.9655 & 58.43 & 65 \\
\hline Rerata Marginal & 74.8785 & 71.5506 & 60.8571 & \\
\hline
\end{tabular}

Tabel 7 Rangkuman komparasi ganda antar baris.

\begin{tabular}{|l|l|l|c|l|}
\hline \multicolumn{1}{|c|}{$\mathbf{H}_{\mathbf{0}}$} & $\mathbf{F}_{\text {obs }}$ & $\mathbf{2 F}_{(\mathbf{0}, 05 ; 2 ; 271)}$ & $\mathbf{D K}$ & Keputusan uji \\
\hline$\mu_{1 \cdot}=\mu_{2} \cdot$ & 6.36 & 6 & $\{\mathrm{~F} \mid \mathrm{F}>6\}$ & $\mathrm{H}_{0}$ ditolak \\
\hline$\mu_{2 \cdot}=\mu_{3} \cdot$ & 6,34 & 6 & $\{\mathrm{~F} \mid \mathrm{F}>6\}$ & $\mathrm{H}_{0}$ ditolak \\
\hline$\mu_{1 \cdot}=\mu_{3} \cdot$ & 25.70 & 6 & $\{\mathrm{~F} \mid \mathrm{F}>6\}$ & $\mathrm{H}_{0}$ ditolak \\
\hline
\end{tabular}

Tabel 8 Rangkuman komparasi ganda antar kolom

\begin{tabular}{|l|l|l|l|l|}
\hline \multicolumn{1}{|c|}{$\mathbf{H}_{\mathbf{0}}$} & \multicolumn{1}{c|}{$\mathbf{F}_{\text {obs }}$} & $\mathbf{2} \mathbf{F}_{(\mathbf{0}, 05 ; 2 ; 271)}$ & \multicolumn{1}{c|}{ DK } & Keputusan uji \\
\hline$\mu_{\cdot 1}=\mu_{\cdot 2}$ & 3.58 & 6 & $\{\mathrm{~F} \mid \mathrm{F}>6\}$ & $\mathrm{H}_{0}$ tidak ditolak \\
\hline$\mu_{\cdot 2}=\mu_{\cdot 3}$ & 32.84 & 6 & $\{\mathrm{~F} \mid \mathrm{F}>6\}$ & $\mathrm{H}_{0}$ ditolak \\
\hline$\mu_{\cdot 1}=\mu \cdot 3$ & 61.53 & 6 & $\{\mathrm{~F} \mid \mathrm{F}>6\}$ & $\mathrm{H}_{0}$ ditolak \\
\hline
\end{tabular}


Tabel 9 Rangkuman komparasi rerata antar sel pada baris yang sama

\begin{tabular}{|l|l|l|l|l|}
\hline $\mathbf{H}_{\mathbf{0}}$ & $\mathbf{F}_{\text {obs }}$ & $\mathbf{8 ~ F}_{(\mathbf{0}, \mathbf{0 5} ; \mathbf{8} 271)}$ & $\mathbf{D K}$ & Keputusan uji \\
\hline$\mu_{11}=\mu_{12}$ & 4.38 & $8(1.94)=15.52$ & $\{\mathrm{~F} \mid \mathrm{F}>15.52\}$ & $\mathrm{H}_{0}$ tidak ditolak \\
\hline$\mu_{12}=\mu_{13}$ & 31.12 & $8(1.94)=15.52$ & $\{\mathrm{~F} \mid \mathrm{F}>15.52\}$ & $\mathrm{H}_{0}$ ditolak \\
\hline$\mu_{11}=\mu_{13}$ & 61.46 & $8(1.94)=15.52$ & $\{\mathrm{~F} \mid \mathrm{F}>15.52\}$ & $\mathrm{H}_{0}$ ditolak \\
\hline$\mu_{21}=\mu_{22}$ & 2.31 & $8(1.94)=15.52$ & $\{\mathrm{~F} \mid \mathrm{F}>15.52\}$ & $\mathrm{H}_{0}$ tidak ditolak \\
\hline$\mu_{22}=\mu_{23}$ & 1.41 & $8(1.94)=15.52$ & $\{\mathrm{~F} \mid \mathrm{F}>15.52\}$ & $\mathrm{H}_{0}$ tidak ditolak \\
\hline$\mu_{21}=\mu_{23}$ & 7.65 & $8(1.94)=15.52$ & $\{\mathrm{~F} \mid \mathrm{F}>15.52\}$ & $\mathrm{H}_{0}$ tidak ditolak \\
\hline$\mu_{31}=\mu_{32}$ & 0.42 & $8(1.94)=15.52$ & $\{\mathrm{~F} \mid \mathrm{F}>15.52\}$ & $\mathrm{H}_{0}$ tidak ditolak \\
\hline$\mu_{32}=\mu_{33}$ & 10.49 & $8(1.94)=15.52$ & $\{\mathrm{~F} \mid \mathrm{F}>15.52\}$ & $\mathrm{H}_{0}$ tidak ditolak \\
\hline$\mu_{31}=\mu_{33}$ & 7.53 & $8(1.94)=15.52$ & $\{\mathrm{~F} \mid \mathrm{F}>15.52\}$ & $\mathrm{H}_{0}$ tidak ditolak \\
\hline
\end{tabular}

Tabel 10 Rangkuman komparasi rerata antar sel pada kolom yang sama.

\begin{tabular}{|l|l|l|l|l|}
\hline $\mathbf{H}_{\mathbf{0}}$ & $\mathbf{F}_{\mathbf{0 b s}}$ & $\mathbf{8} \mathbf{F}_{(\mathbf{0}, \mathbf{0 5} ; \mathbf{8} ; \mathbf{2 7 1})}$ & $\mathbf{D K}$ & Keputusan uji \\
\hline$\mu_{11}=\mu_{21}$ & 7.83 & $8(1.94)=15.52$ & $\{\mathrm{~F} \mid \mathrm{F}>15.52\}$ & $\mathrm{H}_{0}$ tidak ditolak \\
\hline$\mu_{21}=\mu_{31}$ & 5.48 & $8(1.94)=15.52$ & $\{\mathrm{~F} \mid \mathrm{F}>15.52\}$ & $\mathrm{H}_{0}$ tidak ditolak \\
\hline$\mu_{11}=\mu_{31}$ & 29.20 & $8(1.94)=15.52$ & $\{\mathrm{~F} \mid \mathrm{F}>15.52\}$ & $\mathrm{H}_{0}$ ditolak \\
\hline$\mu_{12}=\mu_{22}$ & 4.71 & $8(1.94)=15.52$ & $\{\mathrm{~F} \mid \mathrm{F}>15.52\}$ & $\mathrm{H}_{0}$ tidak ditolak \\
\hline$\mu_{22}=\mu_{32}$ & 0.01 & $8(1.94)=15.52$ & $\{\mathrm{~F} \mid \mathrm{F}>15.52\}$ & $\mathrm{H}_{0}$ tidak ditolak \\
\hline$\mu_{12}=\mu_{32}$ & 5.10 & $8(1.94)=15.52$ & $\{\mathrm{~F} \mid \mathrm{F}>15.52\}$ & $\mathrm{H}_{0}$ tidak ditolak \\
\hline$\mu_{13}=\mu_{23}$ & 5.82 & $8(1.94)=15.52$ & $\{\mathrm{~F} \mid \mathrm{F}>15.52\}$ & $\mathrm{H}_{0}$ tidak ditolak \\
\hline$\mu_{23}=\mu_{33}$ & 4.95 & $8(1.94)=15.52$ & $\{\mathrm{~F} \mid \mathrm{F}>15.52\}$ & $\mathrm{H}_{0}$ tidak ditolak \\
\hline$\mu_{13}=\mu_{33}$ & 0.07 & $8(1.94)=15.52$ & $\{\mathrm{~F} \mid \mathrm{F}>15.52\}$ & $\mathrm{H}_{0}$ tidak ditolak \\
\hline
\end{tabular}

PEMBAHASAN HASIL ANALISA

\section{DATA}

\section{Hipotesis Pertama}

Berdasarkan hasil analisis variansi dua jalan rancangan $3 \times 3$ dengan sel tidak sama untuk efek utama A (model pembelajaran) diperoleh $\mathrm{F}_{\mathrm{a}}=8.10>3.00=\mathrm{F}_{\text {tabel }}$. Ini berarti terdapat perbedaan yang signifikan antara prestasi belajar matematika siswa yang menggunakan model pembelajaran kooperatif tipe Jigsaw berorientasi penemuan terbimbing dengan penggunaan alat peraga, pembelajaran kooperatif tipe Jigsaw dan model pembelajaran konvensional. Dilihat dari uji lanjut antar baris dengan melihat rerata marginalnya jika $\mathrm{H}_{0 \mathrm{~A}}$ ditolak diketahui bahwa, model pembelajaran kooperatif tipe Jigsaw yang berorientasi penemuan terbimbing dengan penggunaan alat peraga memberikan prestasi belajar matematika yang lebih baik dari kooperatif tipe Jigsaw dan keduanya lebih baik dari pembelajaran konvensional.

\section{Hipotesis Kedua}

Berdasarkan hasil analisis variansi dua jalan rancangan $3 \times 3$ dengan jumlah sel tidak sama untuk efek utama B (kemampuan penalaran matematika) diperoleh $\mathrm{F}_{\mathrm{b}}=32.74>3.00=\mathrm{F}_{\text {tabel }}$. Ini berarti bahwa terdapat perbedaan yang signifikan antara prestasi belajar matematika siswa yang memiliki kemampuan penalaran tinggi, sedang, dan rendah. Dilihat dari uji lanjut antar kolom dengan melihat rerata marginalnya jika $\mathrm{H}_{0}$ ditolak diketahui bahwa kemampuan penalaran matematika tinggi mempunyai prestasi belajar matematika yang sama dengan kemampuan penalaran matematika sedang dan keduanya lebih 
baik dari kemampuan penalaran matematika rendah.

\section{Hipotesis Ketiga}

Berdasarkan hasil anava dua jalan dengan sel tidak sama diperoleh harga statistik uji $\mathrm{F}_{\mathrm{ab}}=5.46$ dan $\mathrm{F}_{\text {tabel }}=2.37$, terlihat bahwa $\mathrm{F}_{\mathrm{ab}}>\mathrm{F}_{\text {tabel }}$ sehingga $\mathrm{F}_{\mathrm{ab}} \notin$ DK, dengan demikian $\mathrm{H}_{0 \mathrm{ab}}$ ditolak. Dilihat dari uji lanjut rerata antar sel pada kolom yang sama serta melihat rerata, yaitu pada kemampuan penalaran tinggi, model pembelajaran kooperatif tipe Jigsaw yang berorientasi penemuan terbimbing dengan penggunaan alat peraga memberikan prestasi belajar matematika yang sama dengan kooperatif tipe Jigsaw, model pembelajaran kooperatif tipe Jigsaw memberikan prestasi belajar matematika yang sama dengan dan model pembelajaran konvensional. Model pembelajaran kooperatif tipe Jigsaw berorientasi penemuan terbimbing dengan penggunaan alat peraga memberikan prestasi belajar matematika yang lebih baik dengan konvensional. Pada kemampuan penalaran sedang dan rendah, model pembelajaran kooperatif tipe Jigsaw yang berorientasi penemuan terbimbing dengan penggunaan alat peraga memberikan prestasi belajar matematika yang sama dengan kooperatif tipe Jigsaw dan konvensional. Hal ini tidak sesuai dengan hipotesis, dimungkinkan karena kekurangan penelitian ini. Kendala penelitian antara lain:

1) Pada pembelajaran kooperatif tipe Jigsaw, sebagian siswa belum mampu untuk memahami dan menjelaskan materi pembelajaran yang menjadi tanggung jawabnya kepada teman-teman dalam kelompok sehingga pada saat kelompok ahli siswa yang mempunyai kemampuan sedang dan rendah hanya mencontoh pekerjaan siswa dengan kemampuan penalaran tinggi.

2) Soal tes berupa pilihan ganda dan hanya satu tipe soal sehingga dalam satu kelas sama yang memungkinkan adanya siswa menjawab dengan tidak jujur sehingga soal tes tidak dapat mengukur kemampuan sebenarnya pada siswa khususnya siswa dengan kemampuan penalaran sedang dan rendah yang cenderung bersikap tidak jujur saat mengerjakan tes prestasi belajar matematika.

3) Siswa dengan kemampuan penalaran matematika sedang dan rendah belum siap dengan model pembelajaran yang diberikan.

4) Sebagian besar siswa masih malu dan tidak berani bertanya pada guru apabila ada materi pelajaran yang kurang jelas.

\section{Hipotesis Keempat}


Berdasarkan hasil anava dua jalan dengan sel tidak sama diperoleh harga statistik uji $\mathrm{F}_{\mathrm{ab}}=5.46$ dan $\mathrm{F}_{\text {tabel }}=2.37$, terlihat bahwa $F_{a b}>F_{\text {tabel }}$ sehingga $F_{a b} \notin$ DK, dengan demikian $\mathrm{H}_{0 \mathrm{ab}}$ ditolak. Dilihat dari uji lanjut rerata antar sel pada baris yang sama serta melihat rerata, yaitu pada model pembelajaran kooperatif tipe Jigsaw yang berorientasi penemuan terbimbing dengan penggunaan alat peraga, kemampuan penalaran matematika tinggi mempunyai prestasi belajar matematika yang sama dengan kemampuan penalaran matematika sedang namun keduanya lebih baik dari kemampuan penalaran rendah. Pada model pembelajaran kooperatif tipe Jigsaw dan konvensional, kemampuan penalaran matematika tinggi mempunyai prestasi belajar matematika yang sama dengan kemampuan penalaran matematika sedang dan rendah.

Ketidak sesuai dengan hipotesis penelitian disebababkan karena kekurangan baik dari pihak guru maupun pihak siswa yaitu:

1) Kekurangan dari pihak guru yaitu:

a) Keterbatasan penelitian ini yang tidak mampu mengontrol variabel-variabel lain di luar kemampuan penalaran matematika siswa.

b) Kondisi saat penelitian tidak memungkinkan untuk membangun suasana belajar yang mendukung disebabkan karena keterbatasan waktu sehingga siswa dengan berbagai tingkat kemampuan penalaran kurang mendapatkan kesempatan terlibat lebih banyak dalam kegiatan pembelajaran, untuk memperoleh pemahaman konsep yang kuat, siswa yang aktif dan konsentrasi hanya siswa yang memiliki penalaran tinggi saja.

c) Soal tes penalaran hanya satu jenis dan dalam satu kelas sama.

d) Pada kooperatif tipe Jigsaw yang berorientasi penemuan terbimbing dengan penggunaan alat peraga dan kooperatif tipe Jigsaw memiliki sintaks yang sama yaitu (1) berdiskusi di kelompok awal, (2) berdiskusi dengan kelompok ahli, (3) berdiskusi dengan kelompom awal dan saling berbagi materi. Sehingga guru kurang memaksimalkan ketiga sintaks tersebut, dalam hal ini guru kurang memperhatikan bagaimana siswa mengevaluasi dan mengkomunikasikan jawaban dan lebih cenderung membantu siswa yang merasa kesulitan.

2) Kekurangan dari pihak siswa 
a) Terdapat siswa kurang jujur dalam mengerjakan soal tes prestasi dikarenakan soal berupa pilihan ganda dan sama untuk seluruh siswa dalam satu kelas.

b) Pada saat pengisian LKS beberapa siswa masih tergantung pada teman kelompoknya dan tidak peduli terhadap cara mendapatkan hasil namun hanya mengetahui hasil akhirnya saja.

c) Dimungkinkan adanya ketidakjujuran siswa pada saat pengisian tes prestasi

d) Ketertarikan dan antusias siswa dalam kegiatan belajar mengajar menurun karena model kooperatif jigsaw dilakukan sebanyak delapan pertemuan sehingga beberapa siswa jenuh.

\section{KESIMPULAN}

Berdasarkan analisa data dan pembahasan, dapat disimpulkan beberapa hal sebagai berikut.

1. Model pembelajaran kooperatif tipe Jigsaw yang berorientasi penemuan terbimbing dengan penggunaan alat peraga memberikan prestasi belajar matematika yang lebih baik dari kooperatif tipe Jigsaw dan keduanya lebih baik dari model pembelajaran konvensional untuk pokok bahasan bangun datar segi empat kelas VII SMP di Kabupaten Ponorogo.

2. Kemampuan penalaran matematika tinggi mempunyai prestasi belajar matematika yang sama dengan kemampuan penalaran matematika sedang dan lebih baik dari rendah namun keduanya mempunyai prestasi belajar matematika yang lebih baik dengan kemampuan penalaran matematika rendah untuk pokok bahasan bangun datar segi empat kelas VII SMP di Kabupaten Ponorogo.

3. Pada kemampuan penalaran tinggi, model pembelajaran kooperatif tipe Jigsaw yang berorientasi penemuan terbimbing dengan penggunaan alat peraga memberikan prestasi belajar matematika yang sama dengan kooperatif tipe Jigsaw. Model pembelajaran kooperatif tipe Jigsaw memberikan prestasi belajar matematika yang sama dengan model pembelajaran konvensional. Model pembelajaran kooperatif tipe Jigsaw berorientasi penemuan terbimbing dengan penggunaan alat peraga memberikan prestasi belajar matematika yang lebih baik dengan model pembelajaran konvensional. Pada kemampuan penalaran sedang dan rendah, model pembelajaran kooperatif tipe Jigsaw yang berorientasi penemuan terbimbing 
dengan penggunaan alat peraga

memberikan prestasi belajar

matematika yang sama dengan

kooperatif tipe Jigsaw dan

konvensional.

4. Pada model pembelajaran kooperatif tipe Jigsaw yang berorientasi penemuan terbimbing dengan penggunaan alat peraga, kemampuan penalaran matematika tinggi mempunyai prestasi belajar matematika yang sama dengan kemampuan penalaran matematika sedang namun keduanya lebih baik dari kemampuan penalaran rendah. Pada model pembelajaran kooperatif tipe Jigsaw dan model pembelajaran konvensional, kemampuan penalaran matematika tinggi mempunyai prestasi belajar matematika yang sama dengan kemampuan penalaran matematika sedang dan rendah.

\section{Saran}

Berdasarkan penelitian ini dapat dikemukakan beberapa saran sebagai berikut:

\section{1) Bagi Guru}

a. Berdasarkan kesimpulan penelitian yang pertama, disarankan sesekali model pembelajaran ini dapat dijadikan sebagai salah satu referensi dalam pembelajaran di kelas. Model ini membutuhkan waktu dan fase yang lebih panjang, akibatnya sangat dimungkinkan muncul kendala teknis dalam pelaksanaannya. Selain itu diperlukan persiapan yang matang oleh guru sehingga apabila pendekatan ini akan digunakan, harus disertai dengan persiapan fasilitas dan pengkondisian siswa yang bisa mendukung proses pembelajaran.

b. Berdasarkan hasil penelitian kedua disarankan sebaiknya sesekali guru memilih berbagai model pembelajaran yang memperhatikan penalaran matematika siswa agar prestasi belajar siswa khususnya untuk kemampuan penalaran rendah dapat meningkat dan guru khususnya wali kelas sesekali perlu melakukan tes penalaran dari lembaga tertentu untuk mengetahui kemampuan penalaran siswa karena informasi tersebut dapat digunakan sebagai umpan balik terhadap keberhasilan siswa dan meningkatkan prestasi belajar siswa.

c. Berdasarkan hasil penelitian ketiga maka pada kemampuan penalaran tinggi, untuk efisiensi dan lebih praktis, guru dapat menerapkan model kooperatif tipe Jigsaw tetapi jika ingin membiasakan siswa kemampuan penalaran tinggi untuk lebih kreatif dalam menuangkan idenya dalam menemukan konsep sendiri dapat diterapkan model 
kooperatif tipe Jigsaw berorientasi penemuan terbimbing dengan penggunaan alat peraga. Pada kemampuan penalaran sedang dan rendah, dapat diterapkan model model kooperatif tipe Jigsaw berorientasi penemuan terbimbing dengan penggunaan alat peraga, kooperatif tipe Jigsaw dan model pembelajaran konvensional, namun untuk efisiensi dan lebih praktis, guru dapat menerapkan model pembelajaran konvensional tetapi jika ingin membiasakan siswa dalam kerja kelompok dan membuat siswa lebih kreatif dalam menuangkan idenya untuk menemukan sendiri konsep matematika dapat diterapkan model kooperatif tipe Jigsaw berorientasi penemuan terbimbing dengan penggunaan alat peraga dan koperatif tipe Jigsaw.

d. Berdasarkan hasil penelitian keempat diperoleh bahwa model pembelajaran kooperatif tipe Jigsaw yang berorientasi penemuan terbimbing dengan penggunaan alat peraga dapat diterapkan kepada siswa dengan kemampuan penalaran tinggi dan sedang, model kooperatif tipe Jigsaw dan model pembelajaran konvensional dapat diterapkan kepada siswa dengan kemampuan penalaran tinggi, sedang atau rendah.

\section{2). Bagi Sekolah}

Kurikulum Tingkat Satuan Pendidikan (KTSP) lebih memfokuskan pada pengembangan potensi individu (bukan penyeragaman). Salah satu alternatifnya adalah sekolah memberikan hak sepenuhnya kepada guru untuk mengembangkan potensi masing-masing individu terutama dalam pembelajaran di kelas. Selain itu, pemanfaatan fasilitas yang ada di sekolah juga harus dioptimalkan agar tidak hanya terkesan sebagai pelengkap fasilitas.

\section{3) Bagi Siswa}

a. Model pembelajaran kooperatif tipe Jigsaw berorientasi penemuan terbimbing dengan penggunaan alat peraga adalah pembelajaran yang mendorong siswa berfikir tentang suatu persoalan dan mereka mencari sendiri cara penyelesaiannya. Pendekatan sehingga menuntut siswa untuk lebih aktif dalam mengembangkan sikap dan pengetahuannya tentang matematika sesuai dengan kemampuan masing-masing sehingga akibatnya memberikan hasil belajar yang lebih bermakna pada siswa. Siswa harus mulai terbiasa dengan aktivitas yang lebih tinggi dalam kegiatan belajar mengajar karena dalam pendekatan ini siswa harus melalui beberapa 
fase untuk mendapatkan pemahaman yang baik tentang suatu materi.

b. Siswa diharapkan memperkaya sumber belajar. Selain buku pegangan dari sekolah ataupun modul yang diberikan guru, pencarian materi pelajaran dari perpustakaan atau dari internet dapat memperkaya pengetahuan siswa dan dapat meningkatkan kemampuan siswa dalam memecahkan permasalahan.

\section{DAFTAR PUSTAKA}

Anita Lie. 2007. Cooperative Learning, Mempraktekkan Cooperative Learning di Ruang Kelas. Jakarta: PT Gramedia Widiasarana Indonesia.
Budiyono. 2009. Statistika untuk Penelitian. Surakarta : Universitas Sebelas Maret Press.

Fajar Shodiq. 2004. Pemecahan masalah, penalaran, dan komunikasi. Disajikan pada Diklat Instruktur atau Pengembang Matematika SMA Jenjang Dasar. Departemen Pendidikan Nasional: Yogyakarta.

Jujun S. Suriasumantri. 1982. Filsafat Ilmu. Jakarta: Gramedia.

Soedjadi. 2000. Kiat Pendidikan Matematika di Indonesia. Departemen Pendidikan Nasional

Sumarsono. 2005. Penerapan Pembelajaran Kooperative Model STAD (Student Team Achievemen Division) dan Model Jigsaw Terhadap Prestasi Belajar Fisika pada Pokok Bahasan Tegangan dan arus Bolak-Balik Ditinjau dari Aktivitas Belajar Siswa. Tesis. Program Pascasarjana Universitas Sebelas Maret. 